\title{
Numerical Study of Fuel Regression in Hybrid Rocket Engine
}

\author{
Jean-Étienne Durand*, Florent Raynaud ${ }^{\dagger}$, Jean-Michel Lamet ${ }^{\ddagger}$, Lionel Tessé ${ }^{\S}$, Jean-Yves Lestrade ${ }^{\mathbb{} I}$ \\ and Jérôme Anthoinell \\ ONERA/DMPE, Université de Toulouse - F-31055 Toulouse - France
}

A new pyrolysis model implemented in CEDRE, the ONERA CFD software, is assessed by comparing numerical simulations and experimental data obtained from the HYCAT hybrid engine firing tests. Such a model takes into account radiation effects, using Monte Carlo method, from reaction products and soot provided by carbonic components released from the fuel during the pyrolysis process. The case without radiation is firstly considered and the fuel regression is compared with the value experimentally obtained from the reference case, HYCAT 12. An academic case is then used to study the effect of oxidizer mass flow, turbulent intensities with the k- $\omega$ SST turbulence model and radiation on fuel regression velocity.

\section{Nomenclature}

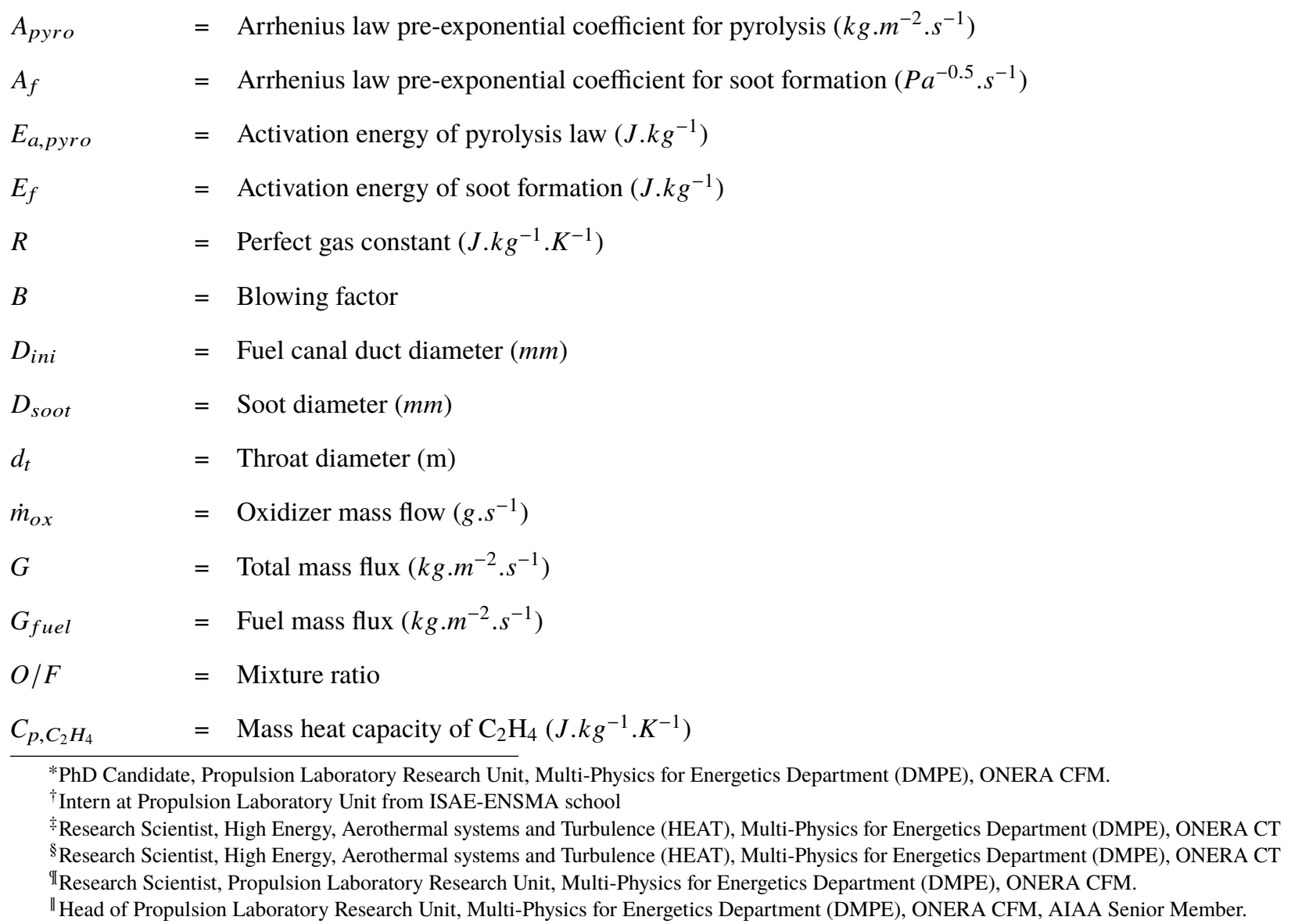




\begin{tabular}{|c|c|c|}
\hline$C_{p, c}$ & $=$ & Mass heat capacity of carbon particles $\left(J \cdot \mathrm{kg}^{-1} \cdot \mathrm{K}^{-1}\right)$ \\
\hline$C_{p, i}$ & $=$ & Mass heat capacity of the $i^{t h}$ species $\left(J \cdot \mathrm{kg}^{-1} \cdot K^{-1}\right)$ \\
\hline$M_{\text {soot }}$ & $=$ & Net mass of soot $(\mathrm{kg})$ \\
\hline$M_{\text {formed soot }}$ & $=$ & Mass of formed soot $(\mathrm{kg})$ \\
\hline$M_{\text {oxidized soot }}$ & $=$ & Mass of oxidized soot $(\mathrm{kg})$ \\
\hline$M_{f}$ & $=$ & Fuel mass (kg) \\
\hline$M_{w}$ & $=$ & Carbon molecular weight $\left(\mathrm{g} \cdot \mathrm{mole}^{-1}\right)$ \\
\hline$\omega_{o x}$ & $=$ & Surface oxidation rate $\left(\right.$ mole.$\left.m^{-2} \cdot s^{-1}\right)$ \\
\hline$P_{c h}$ & $=$ & Chamber pressure (bar) \\
\hline$Q_{c}$ & $=$ & Thermal convective heat flux $\left(W . m^{-2}\right)$ \\
\hline$Q_{r a d}$ & $=$ & Gaseous phase radiative heat flux $\left(W . m^{-2}\right)$ \\
\hline$Q_{r, s}$ & $=$ & Soot radiative heat flux $\left(W . m^{-2}\right)$ \\
\hline$T_{c h}$ & $=$ & Chamber temperature $(\mathrm{K})$ \\
\hline$T_{f l}$ & $=$ & Flame temperature $(\mathrm{K})$ \\
\hline$T_{g}$ & $=$ & Gas phase temperature $(\mathrm{K})$ \\
\hline$T_{w}$ & $=$ & Fuel surface temperature $(\mathrm{K})$ \\
\hline$T_{\text {ref }}$ & $=$ & Reference temperature $(\mathrm{K})$ \\
\hline$y_{C_{2} H_{4, w}}$ & $=$ & Mass fraction of $\mathrm{C}_{2} \mathrm{H}_{4}$ \\
\hline$y_{c, w}$ & $=$ & Mass fraction of carbon particles \\
\hline$y_{v}$ & $=$ & Mass fraction of soot \\
\hline$\Delta H_{f}^{\circ}$ & $=$ & Standard enthalpy of formation $\left(J . \mathrm{kg}^{-1}\right)$ \\
\hline$\Delta H_{f, s}^{\circ}$ & $=$ & Solid fuel standard enthalpy of formation $\left(J \cdot \mathrm{kg}^{-1}\right)$ \\
\hline$\Delta H_{v, e f f}$ & $=$ & Required enthalpy for pyrolysis $\left({\left.\mathrm{J} . k \mathrm{~g}^{-1}\right)}^{-1}\right.$ \\
\hline$\dot{r}$ & $=$ & Fuel regression velocity $\left(m m . s^{-1}\right)$ \\
\hline$v_{r e g, m}$ & $=$ & Mean fuel regression velocity $\left(m m . s^{-1}\right)$ \\
\hline$\rho_{f}$ & $=$ & Solid fuel density $\left(\mathrm{kg} . \mathrm{m}^{-3}\right)$ \\
\hline$\rho_{\text {soot }}$ & $=$ & Soot density $\left(k g . m^{-3}\right)$ \\
\hline$\sigma$ & $=$ & Stefan-Boltzmann constant $\left(W \cdot m^{-2} \cdot K^{-4}\right)$ \\
\hline$\lambda \lambda_{g}$ & $=$ & Gas phase thermal conductivity $\left(W \cdot m^{-1} \cdot K^{-1}\right)$ \\
\hline$\phi_{\text {rad }}^{\text {net }}$ & $=$ & Net radiative heat flux through the fuel surface $\left(W \cdot m^{-2}\right)$ \\
\hline$\phi_{t}$ & $=$ & Total heat flux $\left(W . m^{-2}\right)$ \\
\hline$\epsilon_{w}$ & $=$ & Emissivity of the fuel surface \\
\hline
\end{tabular}




$\begin{array}{ll}\epsilon_{g} & =\text { Gas phase emissivity } \\ \alpha_{g} & =\text { Gas phase absorptivity } \\ k_{g} & =\text { Absorption coefficient of the gas phase } \\ \mu & =\text { Dynamic viscosity }\left(k g . \mathrm{m}^{-1} \cdot \mathrm{s}^{-1}\right) \\ \psi_{v} & =\text { soot mass fraction }\end{array}$

\section{Introduction}

The most common configuration of a hybrid engine (figure 1 has an oxidizer (stored as a liquid and vaporized in the forward dome of the motor or gasified by flowing through a catalyst bed) which flows through long fuel channels and burns with the pyrolysis gases resulting from the solid fuel regression to form a turbulent boundary layer. In this case, the solid fuel is cast in the combustion chamber as for the solid rocket motor technology whereas the oxidizer is stored in a proper tank as in the liquid propulsion technology. The convective and radiative heat fluxes stemming from the diffusion flame provide the energy needed for the solid grain pyrolysis in order to sustain heterogeneous combustion [2, 3]. Such a cycle makes from hybrid combustion a self-sustained phenomenon which occurs as a macroscopic diffusion flame. This implies a dependency of the fuel regression rate on the heat and mass transfer processes. This stabilized combustion continues as long as the oxidizer is injected and the solid fuel grain is regressing. The extinction of the engine can be obtained by closing the oxidizer valve.

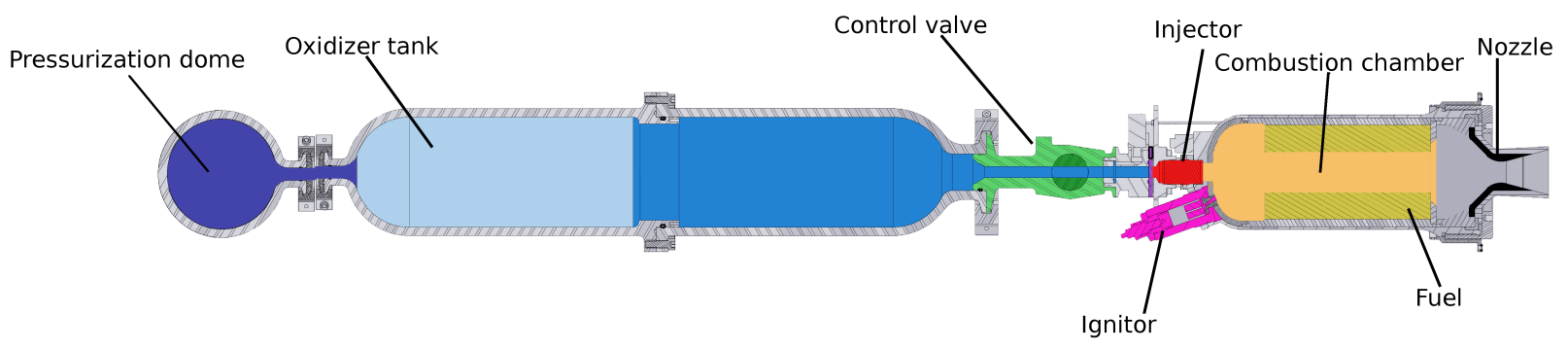

Fig. 1 Classical concept of a hybrid chemical engine

The HYPROGEO project, an European Research and Innovation programme Horizon H2020, aimed at designing and developing an apogee kick motor for geostationary orbit with the hybrid technology [1]. The conventional design of the hybrid rocket is not suitable for the long burning time and constant thrust required for a satellite application for two main reasons. The typical fuel regression rate (about $1 \mathrm{~mm} / \mathrm{s}$ ) would require a too large combustion chamber for the long burning time. Secondly, to keep constant performances, the oxidizer to fuel mixture ratio must be constant as well. However, in the conventional hybrid engine design with a central duct, as the fuel regresses radially, a shift of the oxidizer to fuel ratio appears decreasing the engine performances. Responsible for the HYPROGEO Work Package 
related to the combustion chamber, ONERA has proposed a new chamber design (MHYCAS) which enables the fuel surface, orthogonal to the engine axis, to regress axially[4]. Thus, the oxidizer to fuel mixture ratio can be kept constant during the engine operation and the length to diameter ratio can be shortened $(L / D<1)$. The oxidizer is injected, in swirl, laterally close to the fuel surface (figure 2) which approaches to the Vortex End-Burning Hybrid configuration. The swirling lateral injection enables the engine to reach beyond $90 \%$ of combustion efficiency and to keep the diffusion flame far from the wall of the chamber (figure 3). This design can show a very good throttlability owing to the control of the oxidizer to fuel ratio by which the fuel regression velocity evolves linearly to the oxidizer mass flow. Testing campaign with the MHYCAS hybrid engine, based on the proposed design, has been carried out in November 2016 to check the ignition and to define the operational condition for the final test campaign with the HYPROGEO demonstrator (SuperMHYCAS), realized in the early 2018[? ].

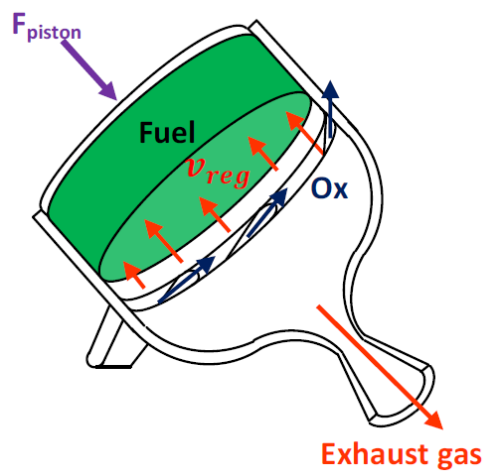

Fig. 2 Hybrid engine design proposed by ONERA

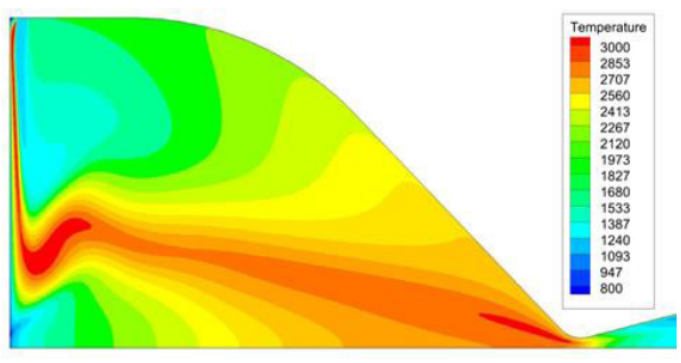

Fig. 3 Temperature field of ONERA hybrid engine with swirling injection[5]

The first numerical simulations of the new configuration, performed without radiation modelling, have shown a very small fuel regression value compared to the experimental data. In such conditions, radiation would play an important role on enhancing the fuel regression velocity [6] and computational results are not physical as radiation is not taken into account. Furthermore, according to Chiaverini et al.[7], soot particles would provide $80 \%$ of the radiant heat flux to the fuel surface. Radiative heat flux would therefore provide the required energy to increase the fuel regression rate by the soot particles from black carbon released during the pyrolysis of black HDPE. Therefore, the pyrolysis phenomenon must be modelled conveniently taking into account radiative effects.

A pyrolysis model has been recently developed and implemented in CEDRE, the CFD software of ONERA. Aiming at checking the impact of radiative heat flux on the fuel regression, the solver CHARME, which computes the reacting multi-species gas flow, is coupled with a radiation solver like ASTRE using Monte-Carlo method or REA processing with the Discrete Ordinate Method. Before using it for the MHYCAS hybrid engine configuration, this pyrolysis model 
needs to be validated from the classical configuration for which combustion process and regression fuel behaviour are far better understood. Firstly, the pyrolysis model without radiative term is considered and assessed by comparing experimental results from HYCAT engine campaign and numerical simulations. Then, the complete pyrolysis model with radiative term is applied to an academic test case in order to conclude on the effect of the radiation from the combustion products and from the soot particles on the fuel regression.

\section{Radiative effects on fuel regression in Hybrid rocket}

\section{A. Previous studies of radiation effects on fuel regression rate}

The radiative heat flux becomes significant in Hybrid rocket using metallized or carbon black solid fuel. In an analytical study, where the regression rate is written in term of the local surface skin friction coefficient based on Lee's model, Whitmore [8] expressed the $\mathrm{O} / \mathrm{F}$ ratio in function of convective and radiative terms. The radiative term was expressed thanks to Stefan-Boltzmann law. He showed that both convective and radiative terms are dependent on the fuel port diameter. Moreover, expressing the ratio between these two terms, he showed that radiation dominates over convection at low oxidizer mass flux and vice versa. He compared his model to the diffusion-limited model established by Marxmann [9] for an engine using acrylonitrile-butadiene-styrene (ABS) and showed that the differences, in the correlations made to the exponent in the Marxman model, appears by neglecting radiation phenomenon. Hence radiation effects need to be taken into account in the model. Marxman et al.[9] and Muzzy et al.[10] have been the first researchers to propose a fuel regression model considering radiative heat flux of the gas phase (eq.(11)).

Marxman's analysis has shown that radiative heat flux contributes to $10 \%$ in fuel regression velocity increase.

$$
\rho_{f} \dot{r}=\frac{Q_{c} e^{-\frac{Q_{\text {rad }}}{Q_{c}}}+Q_{\text {rad }}}{\Delta H_{v, e f f}}
$$

Where, according to the diffusion-limited theory:

$$
Q_{c}=0.036 \Delta H_{v, e f f}\left(\frac{G x}{\mu}\right)^{-0.2} B^{0.23}
$$

B is the blowing number, representing the similitude parameter for the boundary layer with wall-injection and a thermochemical parameter which characterizes enthalpy exchanges between flame and the wall implying fuel regression. The radiative exchange term is expressed by:

$$
Q_{r a d}=\sigma \epsilon_{w}\left(\epsilon_{g} T_{f l}^{4}-\alpha_{g} T_{w}^{4}\right)
$$

A small amount of radiant heat flux would not affect significantly the regression velocity as radiation flux enables mass 
transfer to increase in the boundary layer involving a stronger adverse heat flux by thermal convection. Hence, only strong radiant heat flux may affect significantly the fuel regression ([9],[10]).

Estey et al.[11] have taken into account radiant heat flux from gas phase:

$$
Q_{\text {rad }}=\sigma T_{g}^{4}\left(1-e^{-k_{g} P_{c h} D}\right)
$$

From this correlation of small and large scale data provided by other researchers, Estey et al. have shown that the consideration of radiant heat flux improves the correlation for metallized fuels whereas the classical convective heat flux theory is the most adapted for hydrocarbon fuels.

Strand et al.[12] carried out hybrid rocket tests, measuring the radiant heat flux, total heat flux and adiabatic flame temperature. From experimental data provided by those tests, they have suggested that the main contribution to radiant heat flux is due to the presence of soot. The radiant heat flux is written as:

$$
Q_{r, s}=\sigma T_{g}^{4}\left(1-e^{-a_{p} N_{p}}\right)
$$

Where $N_{p}$ is the particle number density and $a_{p}$ is a constant. The term $a_{p} N_{p}$ depends on the mass fraction of radiative particles:

$$
a_{p} N_{p}=0.134 \frac{\alpha_{p} P_{c h}}{1+O / F-\alpha_{p}}
$$

Where $O / F$ is the oxidizer to fuel ratio and $\alpha_{p}$ is the mass fraction of soot particles. Due to their size $(0,1-0,005 \mu m)$, particles reach very quickly the thermal equilibrium and emit thermal radiation over the whole infrared spectrum. Hence, the temperature of soot particles can be assumed to be equal to surrounding gas temperature [8]. Strand et al.[12] have concluded that particle radiation from soot is a significant heat source for solid fuel pyrolysis. Typically, they have shown that the total radiant heat flux, considering gas phase products and soot, can reach more than $50 \%$ of the total heat flux, far beyond that earlier researchers have postulated.

Chiaverini et al.[7] have found clues of the impact of radiant heat flux by observing the fuel regression behaviour when oxidizer mass flux decreases (figure 4). The pressure affects the fuel regression evolution in the low oxidizer mass flux region where higher pressure causes higher regression rate. Without radiation, the fuel regression would follow linearly the trend in the figure 4 as only turbulent convective heat transfer governs the fuel regression rate.

From data provided by Strand et al.[12], Chiaverini et al.[7] analyzed also that the contribution of soot particles to the total radiant heat transfer accounts for about $80 \%$. Soot emissivities have also been calculated: the value $(0.12-0.23)$ is ten times higher than that related to gas phase products $(0.013-0.033)$. The addition of $4 \%$ of carbon black particles in the HTPB enables the equivalent emissivity of soot to reach 0.5 [7]. Hence, the soot and carbon residues produced 


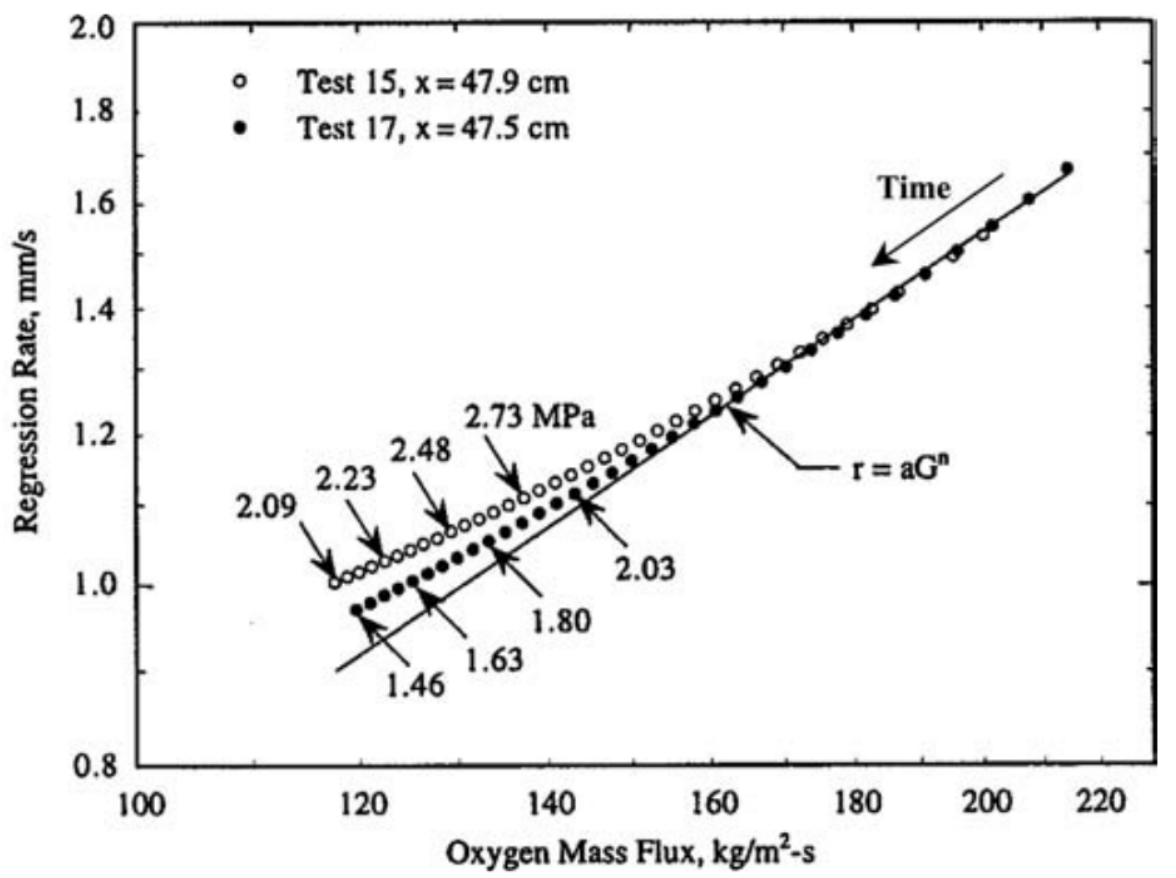

Fig. 4 Pressure effect on fuel regression by radiation phenomenon for HTPB/GOX[6]

during the pyrolysis process of the solid fuel contribute mainly to the radiative effect on the fuel regression rate and the pressure sensitivity at low mass flux regime.

Soot absorption coefficient depends strongly on the oxidizer to fuel ratio but weakly on pressure. Glassman[13] stated that soot concentration depends firstly on temperature and weakly on pressure. Nevertheless this result may be valid only for combustion of HTPB with oxygen. For other oxidizer and solid fuel, like HDPE, the soot tendencies would be different.

\section{B. Radiation models employed in Computational Fluid Dynamics}

According to literature, several approaches have been adopted for radiation modelling. In most studies on fuel regression rate hybrid rockets, radiation is neglected ([14-19]) assuming that this phenomenon would be significant only for metallized fuels. However Chiaverini et al.[7] have shown that for relatively low oxidant flows, radiation could have a significant effect on the fuel regression rate even though the importance of this effect is particularly controverted in the literature. Bianchi et al.[20] have neglected radiation when studying HTPB regression in several oxidizer flux configurations $\left(40 \mathrm{~kg} / \mathrm{m}^{2} / \mathrm{s}\right.$ to $\left.150 \mathrm{~kg} / \mathrm{m}^{2} / \mathrm{s}\right)$ and observed that the regression rate was systematically underestimated, particularly for low mass flux where the error was up to $35 \%$. They did similar observations in a study on a GOX/HDPE hybrid motor. By considering HTPB and HDPE fuels, Faenza et al. [21] observed an underestimations of fuel regression rates. Larger errors for HTPB than HDPE have been found probably because of the soot particle effect on radiant heat 
transfer which becomes important compared to the thermal convective heat flux.

Several studies, such as Whitmore et al.[8], use the Stefan-Boltzmann law for modelling the radiative heat flux:

$$
Q_{\text {rad }}=\sigma\left(\epsilon T_{f l}^{4}-\alpha T_{w}^{4}\right)
$$

Where $\epsilon$ is the emissivity of the gas phase and $\alpha$ is the absorptivity of the fuel grain surface. This radiation term is therefore introduced in the energy balance equation of the gas-solid interface. This model can be improved using the aforementioned correlation established by Estey et al.[11]. To take into account the soot particles effect on radiant heat flux on the solid fuel surface, the correlation established by Strand et al. can be used [12]. Alternatively, Cheng also found a predominance of radiative heat flux on total heat flux in his study on HTPB [22]. He observed that most of the heat at the surface was provided by radiation which is contradictory to empirical correlations where regression rate is proportional to oxidizer mass flux 0.8 powered. He compared experimental results with CFD simulations taking into account turbulence, chemical reactions and radiations and proposed a radiation model using an emissivity of 0.55 . He introduced a blowing rate to balance the convective and radiative heating to the wall against the heat of pyrolysis. The radiation was crudely estimated by this process. Unfortunately experimental results and radiation model weren't sufficiently available to validate this process for more generic application.

Bianchi and al.[20] compared CFD simulations without radiation model and with a Discrete Transfer Method (DTM) radiation model with a grain wall emissivity of 0.85 . This method involves the tracing of representative rays from one surface to another through the domain of interest. The radiant intensity distribution along each ray is calculated by solving a discretization of the Radiative Transfer Equation (RTE). Thus, the discrepancy between numerical simulations and experimental data decreases by considering radiation model (about $40 \%$ error against $15 \%$ error on the regression rate). Bianchi et al.[20] have recorded numerically a strong influence of radiation for low oxidizer mass flux, also observed experimentally by Chiaverini[7]. Leccese et al.[23,25] used the DTM to take into account the radiative heat flux from the incident wall on the fuel surface. On the other hand, the experimental radiative heat flux has been obtained thanks to spectroscopy measurements by integrating over wavelengths the gathered emission spectra. However the results showed a mismatch, probably due to a lack of soot modelling. In another study on HTPB [26], a strong dependency of radiative heat flux on chamber pressure and port diameter has been observed, predicted analytically by Whitmore et al.[8]. Leccese et al. have implemented the radiative heat transfer model without considering soot or carbon black particles even though this is planned for their future studies.

Kim et al.[27] were the first to introduce a radiative soot model for hybrid rocket numerical computations. The 
impact of soot in radiation is described by the soot mass fraction:

$$
y_{v}=\frac{\rho_{\text {soot }} \psi_{v}}{\rho}
$$

A mass transport equation for soot introduces a source term which considers the soot particle generation and oxidation of those particles. The distribution of soot is assumed mono-disperse with a particle size diameter equal to $10^{-8}$. In this model soot is produced according to an Arrhenius law and the fuel mass:

$$
\frac{d M_{\text {soot }}}{d t}=\frac{d M_{\text {formed soot }}}{d t}-\frac{d M_{\text {oxidized soot }}}{d t}=A_{f} P^{0,5} e^{-\frac{E_{f}}{R T}} M_{f}-\frac{6 M_{w}}{\rho_{\text {soot }} D_{\text {soot }}} M_{\text {soot }} \omega_{\text {ox }}
$$

The finite volume method (FVM) is used to solve the radiative transfer equation (RTE) which is integrated over a control volume. Kim has observed that soot distribution depends highly on local O/F ratio and the combustion chamber temperature. The simulations have shown that radiative contribution accounts for $60 \%$ of total heat flux except close to the injector where temperatures are lower and thermal convective heat flux prevails. Even though the solution fits with the exact solution provided by Dua and Cheng [28], no comparison with experimental data has been reported and the model remains therefore invalidated.

Glowacki and al.[29] used the Discrete Ordinate Method to simulate radiation heat transfer of vortex combustion in a hybrid rocket using HTPB. Gariani et al.[30] and Coronetti et al.[31] have used the P-1 Method to treat thermal radiation in the gas flow as an approximation of the P-N method which uses harmonic approximations to compute the incident radiant heat flux F. The diffusion equation is written as:

$$
\nabla \cdot(\Gamma \nabla F)-a F+4 a \sigma T^{4}=0
$$

which is solved with the Marshak boundary condition [32]. a is the absorptivity, $\sigma$ is the Stefan-Boltzmann constant, $\Gamma$ is a constant depending on absorptivity and scattering. Hence, the thermal radiative heat flux is written as:

$$
Q_{\text {rad }}=a F-a \sigma T^{4}
$$

However, no discussion appears about the effect of such a radiation method to assess its relevance on regression model improvement.

It would appear that use of the Monte Carlo Method for modelling radiative heat transfer in hybrid rocket hasn't been published yet. 


\section{Experimental set-up}

To assess the relevance of the numerical models and CFD results, experimental data are required from instrumented lab-scale engine, such as the HYCAT facility (Figure 5). The HYCAT facility is made up of four parts (figure 57: a catalyzer injector, a combustion chamber, a post-chamber and a nozzle. This facility was designed to be able to change the length of each engine part and the fuel grain type [3]. Even though different propellants can be used, those involved in this paper are HDPE for the fuel and $\mathrm{h}_{2} \mathrm{O}_{2}$ for the oxidizer.

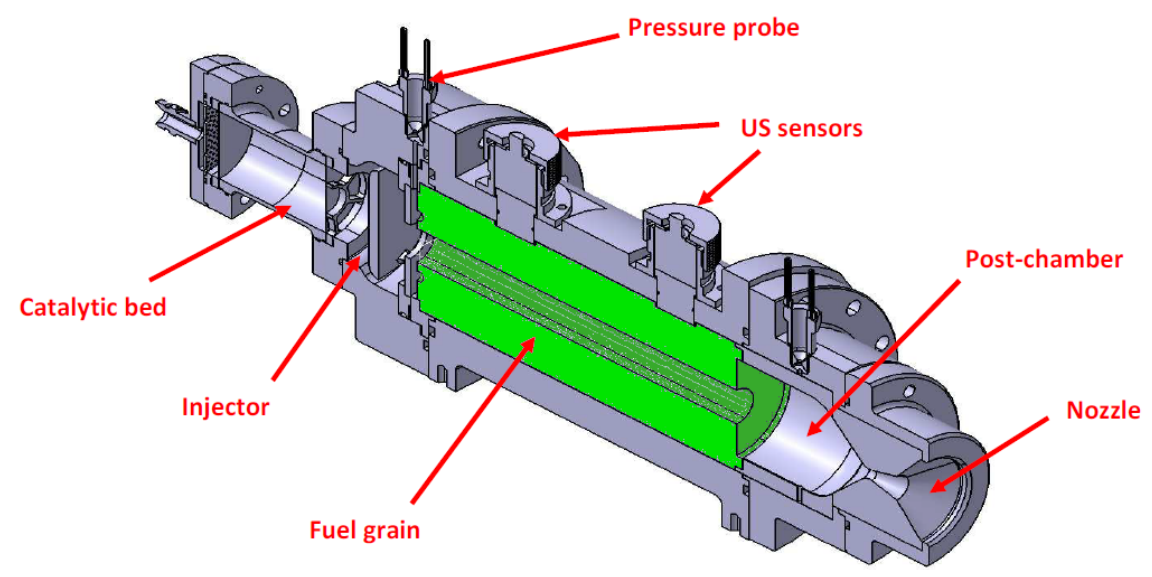

Fig. 5 HYCAT facility

The engine, which can operate until 7.5 MPa, is instrumented with a Coriolis mass flow meter for the oxidizer and four pressure probes (two just before the combustion chamber and two in the post-chamber) and is connected to a thrust sensor to get the propulsive performances. Temperature and pressure measurements of the liquid oxidizer just upstream of the injector are also included. In order to measure the fuel regression rate instantaneously, the engine is also instrumented with ultrasonic sensors (one located at the head-end of the fuel grain and two at the rear-end) [33, 34]. Pulse-echo technique is non intrusive and easily to set up compared with visualization and X-rays measurement techniques.

A catalytic injector, which enables the combustion efficiency to increase relatively to a classical atomizer, is used[35]. The catalyzer decomposes the hydrogen peroxide into hot gaseous oxygen and steam water which is then injected through a gaseous injector directly within the combustion chamber without using a pre-chamber. The injection of a hot gaseous oxidizer is expected to improve the mixture with the pyrolysis gas provided by the fuel grain and to avoid losing a part of the generated heat flux to vaporize and warm the liquid oxidizer. The catalytic injector combines a liquid injector plate, a decomposition chamber containing the catalyst particles and a gaseous injector (figure 6). The injector plate was designed in order to spread all the liquid hydrogen peroxide through the cross section of the decomposition chamber. This chamber consists of an Inconel cylinder closed by refractory steel meshed in order to maintain the catalyst particles inside the decomposition chamber. The catalyst, developed and provided by Heraeus, is a Pt based catalyst supported 
on $\mathrm{Al}_{2} \mathrm{O}_{3}$ material[36]. With the use of catalytic bed, no pyrotechnic device is required to ignite the hybrid engine, improving the safety. The ignition occurs owing to the energy supplied from the hot oxidizer flow. The catalytic bed has therefore to provide a very good efficiency related to a short transient time. A multi-pulsed operation of the hybrid engine is thereby possible as well. The decomposition temperature is measured at the outlet of the catalytic bed thanks

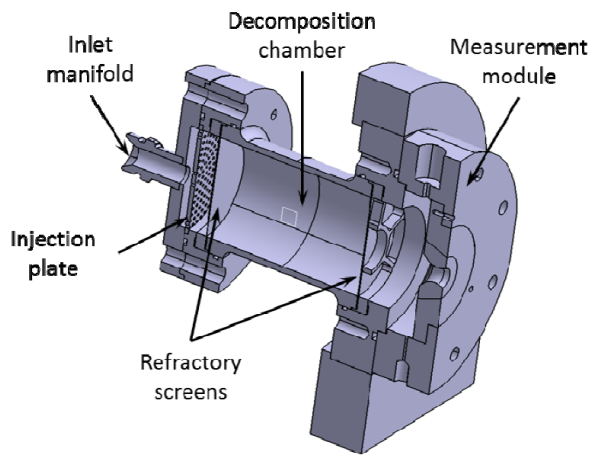

Fig. 6 Catalytic injector

to three thermocouples. The measurement of the decomposition chamber pressure enables to obtain the characteristic curve (oxidizer mass flow rate as a function of the pressure differential) of this chamber in order to precisely control the operating conditions of the mono-propellant tests and the hybrid firing tests. The synoptic diagram of the measurement chain is indicated in figure 7

Almost all tests of the HYCAT facility used a swirl injection for the oxidizer except for the 12th firing where an

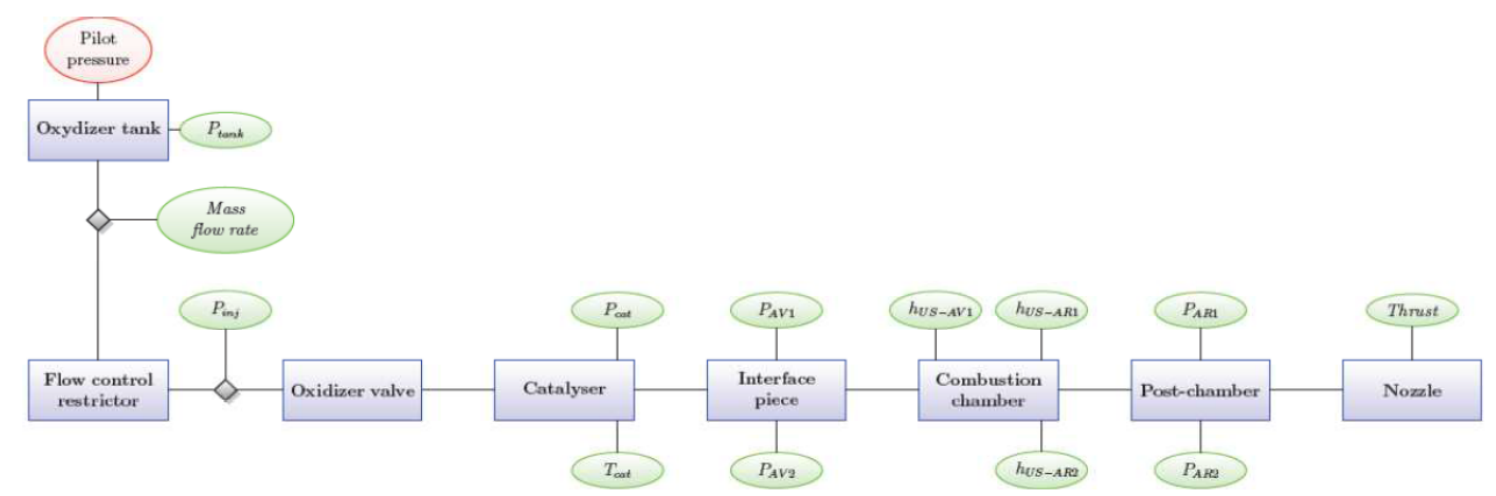

Fig. 7 Synoptic diagram of the measurement chain of the HYCAT hybrid engine

axial injection was used. HYCAT 12 is therefore the reference case of simulations with the pyrolysis model described below. The fuel grain has a $25 \mathrm{~mm}$ diameter single-circular port and a $240 \mathrm{~mm}$ length, and the nozzle is conical. The oxidizer is injected axially. Figures 8 provides the temporal evolutions of the combustion chamber pressure, the oxidizer mass flow rate, the thrust and the oxidizer decomposition temperature for the hybrid test with the axial injector. 


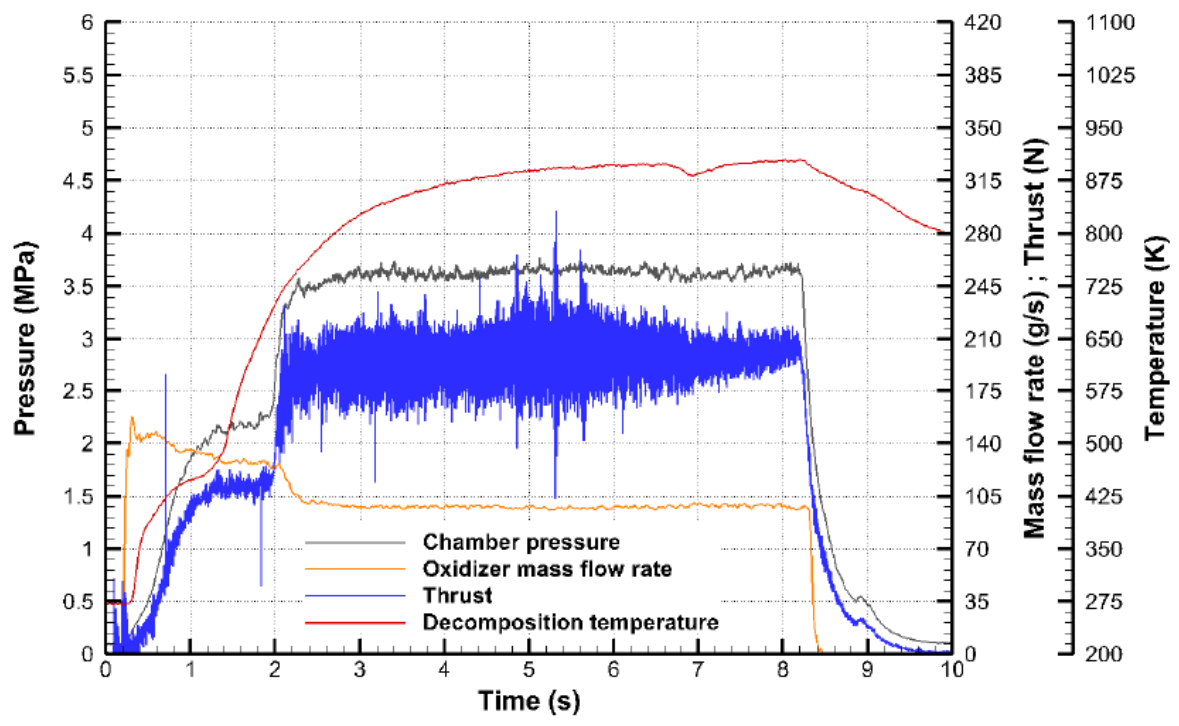

Fig. 8 Firing test with catalyzer and the axial gaseous injector

A mono-propellant phase precedes the hybrid mode. When combustion occurs, the diffusion flame increases the chamber temperature and then the characteristic velocity with the effect to provide a higher combustion chamber pressure. This pressure increase reduces the oxidizer mass flow rate compared to its amplitude during the mono-propellant phase. Larger pressure oscillations occurred for axial injector case compared with the swirl injector case in which mixing is enhanced between the hot gaseous oxidizer and the pyrolyzed fuel [3]. The temperature recorded at the outlet of the decomposition temperature reaches about $875 \mathrm{~K}$, just before the extinction of the engine. The averaged characteristics of the reference test are displayed in table 1 .

Table 1 HYCAT 12: reference case

\begin{tabular}{lccccccc}
\hline case & $\dot{m}_{o x}\left(\mathrm{~g} . \mathrm{s}^{-1}\right)$ & $O / F$ & $\mathrm{v}_{\text {reg, } m}\left(\mathrm{~mm} \cdot \mathrm{s}^{-1}\right)$ & $\mathrm{P}_{c h}(\mathrm{MPa})$ & $\mathrm{D}_{\text {ini }}(\mathrm{mm})$ & $\mathrm{L}_{f u e l}(\mathrm{~mm})$ & $d_{t}(\mathrm{~mm})$ \\
\hline HYCAT 12 & 97.7 & 13.3 & 0.39 & 3.6 & 25 & 240 & 7 \\
\hline
\end{tabular}

\section{Numerical models}

The simulations of the flow in the HYCAT engine are carried out with the ONERA's CFD code, CEDRE software [37]. As the catalyzers decompose the hydrogen peroxide into gaseous products and the pyrolysis produces only gaseous ethylene, the flow in the chamber is assumed only in gas phase. Hence, two kinds of solvers of the CEDRE code are used: CHARME which solves the flow in a reacting multi-species gas, and REA or ASTRE which solves the radiation effects in the flow and on the boundaries. Here, the solver ASTRE, based on the Monte-Carlo Method, is used [38]. 


\section{A. Monte Carlo Method applied to Hybrid rocket CFD simulations}

Radiation effects on combustion gas temperature are supposed negligible because volume radiative losses are small compared to heat release rate. Consequently, there is no need to compute radiative powers (source term in energy conservation equation) in the reactive flow. Moreover, radiative fluxes on chamber and nozzle walls are not needed in this study. Therefore to avoid expensive radiation computation cost, only radiative fluxes on the solid HDPE-type fuel surface are computed.

This kind of calculation is possible with the use of the Emission Reciprocity Method (ERM) [39, 40] of the radiative transfer solver ASTRE [38, 41] based on Monte Carlo Method (MCM) [38, 42]. MCM (including ERM) consists of following a finite large number of energy bundles (discrete amounts of energy, which can be pictured as a group of photons bound together) throughout their transport histories, from emission to absorption. However ERM is slightly different from a classical MCM. Indeed in ERM, there is no need to emit energy bundles from everywhere in the whole computation domain, hoping a sufficient number of bundles will reach the cells where radiative quantities are needed. In ERM, energy bundles have only to be emitted from the cells where radiative quantities are needed and incident radiative energies on these cells are obtained by applying reciprocity principle along all energy bundle paths leaving these cells.

To compute radiative fluxes on the solid HDPE-type fuel surface assumed to be grey, diffuse and discretized in $N_{f}$ boundary faces, emitted fluxes (in Watts) are first computed by

$$
\phi_{i}^{e}=\pi A_{i} \epsilon_{i} \int_{0}^{+\infty} I_{v}^{\circ}\left(T_{i}\right) d v=A_{i} \epsilon_{i} \sigma T_{i}^{4}
$$

where $i$ is the boundary face index $\left(1 \leq i \leq N_{f}\right), A_{i}$ the area $\left(m^{2}\right)$ of the face $i, \epsilon_{i}$ the diffuse grey emissivity chosen by the user, $I_{v}^{\circ}$ the Planck's distribution, also called black-body intensity $\left(W \cdot \mathrm{m}^{-2} \cdot \mathrm{Sr}^{-1} . \mathrm{cm}^{-1}\right), \sigma$ the Stefan constant equal to $5.6710^{-8} \mathrm{~W} \cdot \mathrm{m}^{-2} \cdot \mathrm{K}^{-4}$ and $\mathrm{T}_{i}$ the temperature $(\mathrm{K})$ on the boundary face $i$.

The number of energy bundles emitted from the boundary face $i$ is given by:

$$
N_{i}=\frac{\phi_{i}^{e}}{\sum_{j=1}^{N_{f}} \phi_{j}^{e}} N
$$

where $N$ is the total number of energy bundles chosen by the user to perform the whole Monte Carlo computation.

Before emitting each bundle, its characteristics (namely emission point, initial direction and wave number) are chosen according to probability distributions by drawing random numbers. To choose an emission point inside a face, a 
uniform probability distribution is considered. The two angles defining the initial direction of the $\mathrm{k}^{\text {th }}$ energy bundle are obtained by [39]:

$$
\theta_{k}=\arccos \left(\sqrt{R_{\theta_{k}}}\right) \quad \varphi_{k}=2 \pi R_{\varphi_{k}}
$$

where $\mathrm{R}_{\theta_{k}}$ and $\mathrm{R}_{\varphi_{k}}$ are two independent random numbers uniformly drawn in $[0,1]$. Wave number $v_{k}\left(\mathrm{~cm}^{-1}\right)$ is determined according to:

$$
R_{v_{k}}=\frac{\int_{0}^{v_{k}} I_{v}^{\circ}\left(T_{r e f}\right) d v}{\int_{0}^{+\infty} I_{v}^{\circ}\left(T_{r e f}\right) d v}=\frac{\pi}{\sigma T_{r e f}^{4}} \int_{0}^{v_{k}} I_{v}^{\circ}\left(T_{r e f}\right) d v
$$

where $\mathrm{R}_{v_{k}}$ is an independent random number uniformly drawn in $[0,1]$ and $\mathrm{T}_{r e f}$ a temperature (chosen by user) representative of the flame radiative emission. In this way, wave numbers characteristic of flame emission are generated. In this study the value of $2800 \mathrm{~K}$ is chosen for $\mathrm{T}_{r e f}$, corresponding to the maximum temperature in the flame.

To compensate the statistical bias introduced in the determination of the wave number, the power transported by the $k^{\text {th }}$ energy bundle leaving the boundary face $i$ is equal to:

$$
P_{i, k}^{i n i}=\frac{A_{i} \epsilon_{i} \sigma T_{r e f}^{4}}{N_{i}} \frac{I_{v_{k}}^{\circ}\left(T_{i}\right)}{I_{v_{k}}^{\circ}\left(T_{r e f}\right)}
$$

Thereby the spectral distribution of the power emitted by the boundary face $\mathrm{i}$ is correctly represented.

When the three characteristics of a bundle are determined, the geometrical trajectory of the $k^{\text {th }}$ energy bundle leaving the boundary face $i$ can be constructed. All the cells crossed by the energy bundle are determined one by one. Absorption phenomenon is treated with the path-length method [42] which consists of computing exponential absorption (Beer law) along the energy bundle trajectory. Therefore, absorbed power is computed in every crossed cell and, by application of the reciprocity principle, every crossed cell contributes to the calculation of the energy incident on the boundary face $i$. A bundle is traced either until it leaves the computational domain or until its energy is depleted below a given cut-off level.

The absorbed power in the $j^{t h}$ cell crossed by the $k^{t h}$ energy bundle emitting by the boundary face $i$ is given by:

$$
P_{i, k, j}^{e a}=P_{i, k}^{i n i} \tau_{v_{k}}(i \rightarrow j)\left[1-\exp \left(-\kappa_{j, v_{k}} l_{j, k}\right)\right]
$$

where $\tau_{v_{k}}(i \rightarrow j)$ is the spectral transmissivity from the emission point on the face $i$ to the inlet point in the cell $j, \kappa_{j, v_{k}}$ the spectral absorption coefficient in the cell $j$ and $l_{j, k}$ the distance travelled in the cell $j$.

By application of the reciprocity principle [39], the power emitted by the cell $j$ and absorbed by the boundary face $i$ 
is equal to:

$$
P_{j, k, i}^{e a}=P_{i, k, j}^{e a} \frac{I_{v_{k}}^{\circ}\left(T_{j}\right)}{I_{v_{k}}^{\circ}\left(T_{i}\right)}
$$

Finally, the radiative flux (W) on the boundary face $i$ writes

$$
\phi_{i}^{R}=\phi_{i}^{a}-\phi_{i}^{e}
$$

where the absorbed flux is given by:

$$
\phi_{i}^{a}=\frac{A_{i} \epsilon_{i} \sigma T_{r e f}^{4}}{N_{i}} \sum_{k=1}^{N_{i}} \frac{1}{I_{\nu_{k}}^{\circ}\left(T_{r e f}\right)} \sum_{j} I_{\nu_{k}}^{\circ}\left(T_{j}\right) \tau_{v_{k}}(i \rightarrow j)\left[1-\exp \left(-\kappa_{j, v_{k}} l_{j, k}\right)\right]
$$

Due to high pressure in the chamber (the steady state chamber pressure is about $3.6 \mathrm{MPa}$, see figure 8 gaseous radiative properties are modelled by using the Statistical Narrow-Band (SNB) model in the weak absorption approximation [38, 43, 44] With this approximation, a mean absorption coefficient can be deduced from SNB model parameters. EM2C band model parameters[45] have been used for $\mathrm{H}_{2} \mathrm{O}, \mathrm{CO}_{2}$ and $\mathrm{CO}$ gaseous species. The spectral interval $\left[137.5-9312.5 \mathrm{~cm}^{-1}\right]$ is divided into 43 spectral bands of variable width.

Soot particles are supposed sufficiently small to be considered at thermal equilibrium with combustion gases and in the Rayleigh regime. Therefore radiation scattering by soot particles is supposed negligible and spectral absorption coefficient (in $\mathrm{m}^{-1}$ ) of soot particles, at a point $P$ of the medium, can be expressed as [38, 41, 46]:

$$
\kappa_{v}^{\text {soot }}(P)=550 v f_{V}(P)
$$

where $v$ is the wave number $\left(\mathrm{in}^{-1}\right.$ ) and $\mathrm{f}_{V}$ the soot volume fraction. 14 spectral bands of width equal to 1000 $\mathrm{cm}^{-1}$ are added to the gas spectral discretization to extend the spectral interval to $23312.5 \mathrm{~cm}^{-1}$.

\section{B. Numerical methods for HYCAT 12}

The simulated reference case, HYCAT 12, presents an axial injection and the problem could be reduced to a 2D axisymmetric field. However, the ASTRE solver can only solve the radiation in 3D flow. A fraction corresponding to $6^{\circ}$ of the engine is therefore simulated considering periodic symmetry. Except for the injection region, the mesh is 3D structured with a cell number equal to about 1000000 according to a mesh convergence (figure 9).

The flow is assumed compressible and steady with two-step chemical reaction based on the Arrhenius law [47]. The considered species are : $\mathrm{C}_{2} \mathrm{H}_{4}(\mathrm{~g}), \mathrm{O}_{2}(\mathrm{~g}), \mathrm{H}_{2} \mathrm{O}(\mathrm{g}), \mathrm{CO}(\mathrm{g})$ and $\mathrm{CO}_{2}(\mathrm{~g})$. The RANS k- $\omega$ model is used to take into 


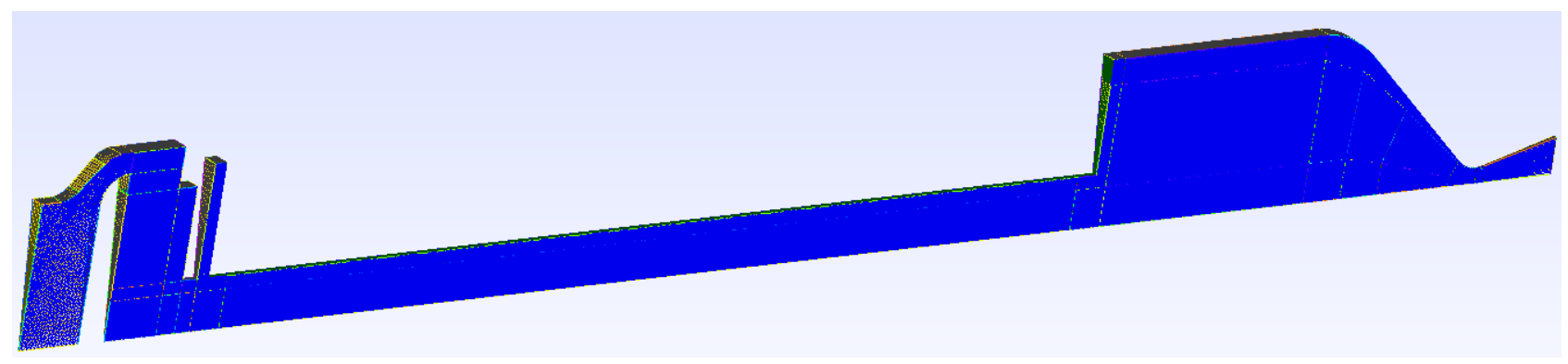

Fig. 9 3D structured mesh of HYCAT 12 configuration

account the turbulence effects on the flow as the estimated Reynolds number, considering the HYCAT 12 case, is equal about to $10^{6}$. The fluctuation model used is the Boussinesq approximation.

The oxidizer flux, injecting a gaseous mixing of steam water and molecular oxygen as catalytic products of $87.5 \%$ $\mathrm{H}_{2} \mathrm{O}_{2}$ at $876 \mathrm{~K}$ and a turbulent intensity of $10 \%$ are set at the inlet and the post-chamber wall and injector wall are assumed adiabatic. A pyrolysis model is newly implemented in CEDRE software to improve the physical relevance of CFD simulations of Hybrid rocket for performance optimization. The fuel mass flow is computed from the energy balance at the solid-gas interface on the fuel grain (eq. (22)). The pyrolysis equation is assumed stationary and the radiative part crossing the fuel, considered opaque, is neglected.

$$
\left.\lambda_{g} \frac{\partial T}{\partial z}\right|_{w^{+}}+\Phi_{\text {rad }}^{\text {net }}=G_{f u e l}\left(y_{C_{2} H_{4}, w}\left(\int_{T_{r e f}}^{T_{w}} C p_{C_{2} H_{4}} d T+\Delta H_{f, C_{2} H_{4}}^{\circ}\right)+y_{c, w} C p_{c}\left(T_{w}-T_{r e f}\right)-\Delta H_{f, s}^{\circ}\right)
$$

The radiative term is obtained directly from the radiant heat flux computed by ASTRE. Carbon particles can provide a significant radiative heat flux reaching $50 \%$ of the total heat flux through the fuel grain surface. As, in hybrid rocket propulsion, the usual solid fuels are polymers like HTPB or HDPE, carbon particle quantity in the flow would be sufficient to provide a substantial contribution in energy to the pyrolyzed fuel. In the present paper, carbon particles are therefore introduced via the pyrolysis phenomenon. According to a thermochemical study carried out specially to improve the knowledge about the used HDPE fuel grain, carbon black sediment has been found and represents $4 \%$ of the total mass of HDPE burnt during thermogravimetric tests.

The carbon particles are considered to be released into the gas flow without reacting or being transformed by the pyrolysis phenomenon. Nevertheless, the sensible enthalpy of solid carbon particles has been taken into account because, numerically, the carbon particle flow is modelled as a "compressible liquid", moving like a gas but governed by a specific equation of state describing a condensed phase behaviour. The fuel mass flow is governed by the pyrolysis law which depends only on temperature. The Arrhenius coefficients related to the considered HDPE, obtained by a TGA 
study, is given in the table 2 .

Table 2 Arrhenius coefficients

\begin{tabular}{cc}
\hline $\mathrm{A}_{\text {pyro }}\left(\mathrm{s}^{-1}\right)$ & $\mathrm{E}_{\text {a,pyro }}\left(\mathrm{kJ} . \mathrm{mole}^{-1}\right)$ \\
\hline $1.27544 \times 10^{14}$ & $236.04 \pm 5.33$ \\
\hline
\end{tabular}

Initially, ethylene is the only pyrolyzed species. Here, even though carbon particles are introduced, the terms related to the mass diffusion of enthalpy are neglected. However, the implemented model is subject to evolve soon to take into account those terms in order to improve the model and to widen the research scope to heterogeneous reactions.

Numerically, the boundary condition related to the pyrolysis is a wall-inlet type condition through which the fuel mass flow is injected. $\mathrm{k}$ and $\omega$ coefficients are set according to the turbulent intensity at the fuel surface $\mathrm{I}_{u}=$ $3,7 \%$ obtained by considering a canal duct. $y^{+}=1$ for a cell transversal length is equal to $5 \mu \mathrm{m}$ over the solid fuel boundary.

Numerical simulations of HYCAT12 are carried out to assess the validity of the pyrolysis law and to propose a view upon future researches about radiation effects by carbon particles release and gas products on fuel regression in hybrid rocket propulsion.

\section{Validation of the pyrolysis model}

Primarily, the computation of HYCAT12 configuration is realized without considering the net radiant heat flux to assess the effect of thermal convection on the fuel pyrolysis $\left(\Phi_{\text {rad }}^{\text {net }}=0\right)$. Furthermore, no carbon particle is introduced and ethylene is the only pyrolysis product $\left(y_{c, w}=0\right.$ and $\left.y_{C_{2} H_{4}, w}=1\right)$. The fuel mass flow from pyrolysis is reported in the table 3 compared with the experimental value. The numerical is three times higher than the experimental value. However, as the experimental fuel regression velocity is averaged, it cannot be directly compared to the numerical value obtained according to the initial diameter.

Table 3 HYCAT 12: CFD vs Experiment

\begin{tabular}{lccc}
\hline case & $\dot{m}_{f, m o y}\left(\mathrm{~kg} . \mathrm{s}^{-1}\right)$ & $\mathrm{v}_{\text {reg }, m}\left(\mathrm{~mm} . \mathrm{s}^{-1}\right)$ & $\mathrm{P}(\mathrm{MPa})$ \\
\hline exp. HYCAT 12 & 0,0074 & 0.39 & 3.6 \\
CFD & 0.021 & 1.11 & 4.1 \\
\hline
\end{tabular}

New analytical tools will be available soon to observe the instantaneous fuel regression from US sensors which will offer a new insight in the experimental fuel regression behaviour. The next simulations will consider other firing instants (other canal duct diameters) to be able to compare the numerical fuel regression velocity and the corresponding experimental value obtained by US sensor analysis. A future testing campaign will be also performed with the HYCAT 
engine in the operating condition of HYCAT 12 and using natural HDPE to consolidate the experimental results obtained.

\section{A. Effects of turbulence and species composition}

A parametric study is carried out with a canal duct configuration as an academic test case for numerical simulations to assess the impact of turbulence on the fuel regression rate (table 4 and figure 10 ). The mesh has 52000 cells. The

Table 4 Academic case for pyrolysis study

\begin{tabular}{lcccc}
\hline case & $\mathrm{P}(\mathrm{MPa})$ & $\mathrm{G}_{o x}\left(\mathrm{~kg} \cdot \mathrm{m}^{-2} \cdot \mathrm{s}^{-1}\right)$ & $\mathrm{D}(\mathrm{mm})$ & $\mathrm{L}(\mathrm{mm})$ \\
\hline Academic case & 4.1 & 200 & 25 & 120 \\
\hline
\end{tabular}

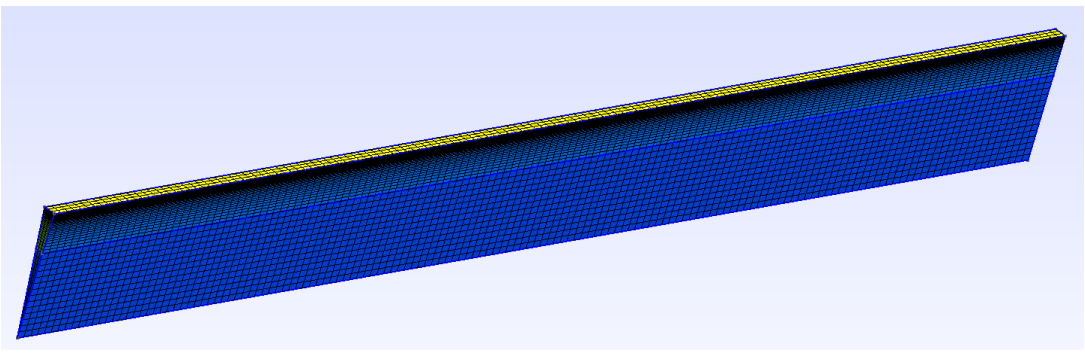

Fig. 10 Mesh of the academic case

considered parameters are the turbulent intensity of oxidizer incoming flow and the one of the pyrolyzed fuel. As the HYCAT simulations, the radiation term is neglected and carbon particles are not introduced. The graph 11 shows that the turbulence intensity of pyrolyzed fuel has no influence on the fuel regression velocity whereas the latter increases linearly with the oxidizer turbulent intensity.

Another way of research is the influence of the pyrolyzed product composition on which the required energy to pyrolyze the fuel depends. Regrouping the conductive, enthalpy mass diffusion and radiation terms in a total heat flux $\Phi_{t}$ through the fuel surface, the energy balance at the gas-solid interface can be expressed by:

$$
\rho_{f} \dot{r} \Delta H_{v, e f f}=\Phi_{t}
$$

Where $\Delta H_{t}$ is the enthalpy required for pyrolysis and gauges thereby the intensity of the fuel regression from a given heat flux to the fuel surface. Hence, a higher pyrolysis enthalpy implies a lower fuel regression considering the same heat flux provided by the flow.

In the current model, ethylene is assumed to be the only pyrolysis product. However, chromatography analysis of gas products from Thermogravimetry analysis of black HDPE shows that, ethylene is not the sole pyrolyzed species but other species like propane and propene are present and proportionally with the same order as ethylene during the TGA 


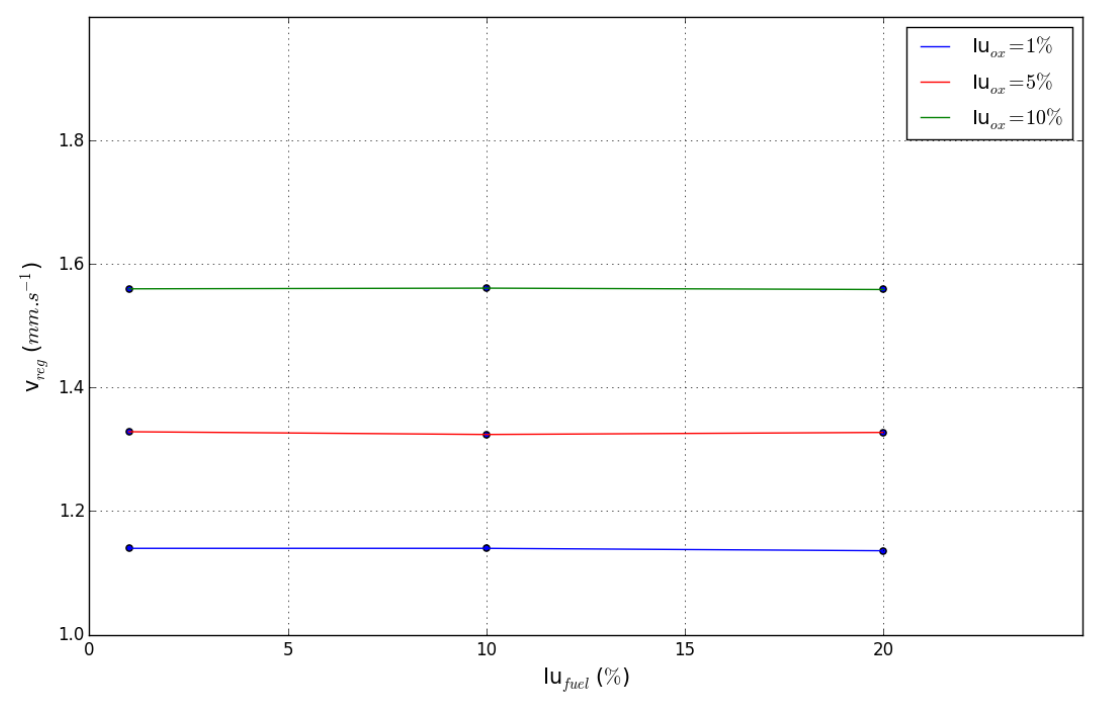

Fig. 11 Fuel regression velocity with fuel turbulent intensity

process (table 5). According to the table 5, some products like propane, butane and pentane present higher absolute

Table 5 Species mass fraction by GC during ATG of black HDPE

\begin{tabular}{lccccccccc}
\hline species & $\mathrm{C}_{2} \mathrm{H}_{4}$ & $\mathrm{C}_{3} \mathrm{H}_{8}$ & $\mathrm{C}_{3} \mathrm{H}_{6}$ & $\mathrm{n}-\mathrm{C}_{4} \mathrm{H}_{10}$ & $1-\mathrm{C}_{4} \mathrm{H}_{8}$ & $\mathrm{n}-\mathrm{C}_{5} \mathrm{H}_{12}$ & $1-\mathrm{C}_{5} \mathrm{H}_{10}$ & $\mathrm{C}_{s}$ & Residuals \\
\hline $\mathrm{y}$ & 0.14 & 0.12 & 0.26 & 0.10 & 0.14 & 0.06 & 0.13 & 0.04 & 0.01 \\
$\Delta h_{f}^{\circ}\left({\left.\mathrm{kJ} . \mathrm{kg}^{-1}\right)}^{1873.21}\right.$ & -2387.05 & 475.95 & -2171.4 & -11.25 & -2032.50 & -442.86 & - & - \\
\hline
\end{tabular}

values of sensible enthalpy and standard formation enthalpy than ethylene. However, most of those products have the standard formation enthalpy negative which lower the required enthalpy, expressed by eq.24. For the reported species distribution at $\mathrm{T}_{s}=1000 \mathrm{~K}$, the required energy to pyrolyze the solid fuel is equal to $1885,4 \mathrm{~kJ} \mathrm{~kg}^{-1}$ whereas, taking into account only ethylene, the value is $3781.3 \mathrm{~kJ}_{\mathrm{kg}} \mathrm{kg}^{-1}$. Hence, using only ethene as pyrolysis products, the required energy to pyrolyze is maximal and therefore the fuel regression rate is minimal. Considering the presented species distribution causes an increase on fuel regression rate.

$$
\Delta H_{t}=\sum_{i=0}^{N_{s}} y_{i}\left(\int_{T_{r e f}}^{T_{w}} C p_{i}(T) d T+\Delta H_{f, i}^{\circ}\right)-\Delta H_{f, s}^{\circ}
$$

Nevertheless, that species distribution must be taken with very careful attention as the decomposition process may be certainly different between the operating condition in hybrid rocket engines and the one used during the TGA ( $\mathrm{P}=10 \mathrm{Bar}$, $\mathrm{T}=920 \mathrm{~K})$. Complementary analysis are currently made to get the standard formation enthalpy of the used black HDPE to know whether the value would be higher enough to reduce the fuel regression rate. 
Even though the pyrolysis model is currently not validated, it has been used to investigate the effect of the radiation from gas products and soot particles on the fuel regression.

\section{Effect of radiation}

A parametric study is carried out by CFD using the academic test case previously described. The radiative term is taken into account in the pyrolysis model as well as the carbon particles in the case of radiation provided by soot. The carbon mass fraction introduced in the flow is equal to $4 \%$. The turbulent intensity is set at $5 \%$ for the oxidizer and the fuel. Because no nozzle is used, the pressure evolution can be decoupled to the oxidizer mass flux, enabling the case to study separately the pressure and oxidizer mass flux evolutions. Hence, the evolution of oxidizer mass flux with a pressure set to $3.6 \mathrm{MPa}$ is considered. The future investigation will also consider the sensitivity of pressure on fuel regression rate by radiation phenomenon.

The evolution of the fuel regression for the three considered cases, radiationless, gaseous phase radiation and soot radiation, is shown on the figure 12 As expected, the introduction of carbon particles enhances the fuel regression velocity for all simulated cases whereas, radiation provided by the gas reaction products seems not to affect the fuel regression rate.



Fig. 12 Fuel regression velocity evolution with oxidizer mass flux

Nevertheless, according to the figure 13 , the difference increases from about $1 \%$ to $6 \%$ when the oxidizer mass flux decreases from $200 \mathrm{~kg} \cdot \mathrm{m}^{-2} \mathrm{~s}^{-1}$ to $10 \mathrm{~kg} \cdot \mathrm{m}^{-2} \mathrm{~s}^{-1}$ for the gaseous phase radiation case.

Taken into account the soot particles, the fuel regression rate increases from $5.5 \%$ to $11,6 \%$ when the oxidizer 


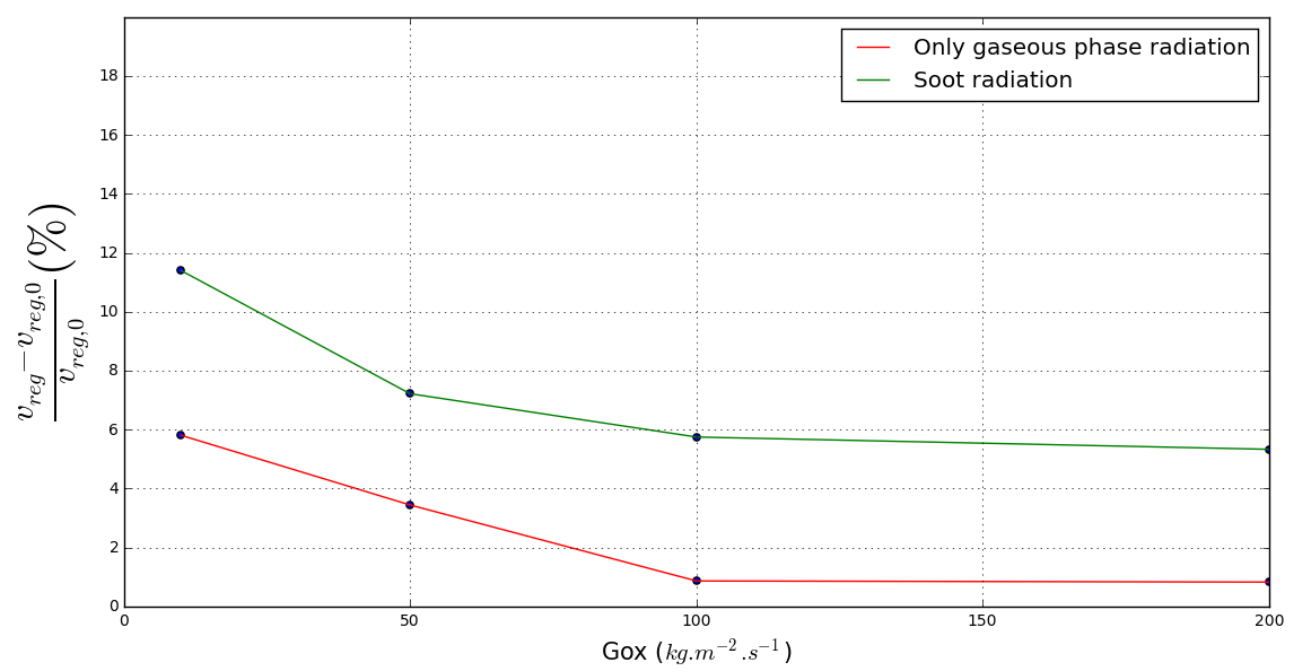

Fig. 13 Differences of fuel regression velocity between radiationless and radiation cases

mass flux decreases. Those trends are expected as, at low oxidizer mass flux, the thermal convection heat flux decreases significantly and radiation contribution becomes therefore important. However, particularly for the soot case, the radiation contribution is lower than thought. In fact, the highest contribution of radiation with carbon particles to fuel regression rate reaches barely $12 \%$. The relatively low value may be explained by the quantity of carbon particles which might be insufficient. In fact, the radiant heat flux term is intimately related to the mass fraction of carbon particles flowing from the fuel surface. This quantity, set to $4 \%$ for the computation, is obtained from TGA iand the conditions of this analysis are obviously questionable. Nonetheless, this constitutes a first approach to model the radiative effect on fuel regression and further investigations must be pursued to define more accurately the contribution of radiation from soot particles.

\section{Conclusion}

The pyrolysis model implemented in the ONERA's software, CEDRE, is assessed by comparing the computed fuel regression rate to the value measured from the HYCAT hybrid engine firing test performed at Fauga-Mauzac ONERA centre. A great overestimation of fuel mass flow from testing data was observed considering k- $\omega$ SST turbulent model and without radiation model. An academic test case was used to study the effect of turbulent intensity and radiation on fuel regression velocity. The latter varies linearly with oxidizer turbulent intensity at the canal duct inlet whereas no change has been observed when increasing fuel turbulent intensity. A very low oxidizer turbulent intensity $\left(\mathrm{I}_{u}<1 \%\right)$ is therefore required to have more reasonable fuel regression velocity. Besides, the potential modification of sensible enthalpy or solid fuel standard formation enthalpy because of the pyrolysis product composition seems to decrease dramatically the pyrolysis enthalpy causing a strong increase on fuel regression rate. The required enthalpy to pyrolyze is maximal 
when ethylene is the unique pyrolysis product and implies a minimal fuel regression value despite the overestimation found in simulations. Hence, composition would not affect positively the fuel regression rate unless standard formation enthalpy of solid fuel, currently in measurement at ONERA, would be higher enough to lower the fuel regression velocity. The validation is therefore in process where numerical problems are still not removed and future development of experimental analysis tools to handle US sensor data would provide further clues on the fuel regression behaviour.

To get an insight into the future investigations in pyrolysis modelling, a prospective study was carried out by simulating a representative flow found in hybrid rocket canal duct with a test case taking into account radiation and black carbon particles, assumed to be released during the pyrolysis process. As expected, when the oxidizer mass flux through the fuel canal duct decreases, the fuel regression velocity decreases as well whereas the relative difference between the radiationless and radiation cases increases. With soot particle in the flow, the fuel regression velocity is increased by about $6 \%$ for high oxidizer mass and by $12 \%$ for low oxidizer mass flux. Gaseous phase radiation could be neglected (1\%) at high mass flux level but it can contribute to $6 \%$ on fuel regression rate at low mass flux level. Sensitivity of pressure is the next step of the study. The relevance of the black carbon introduction in the flow has to be assessed in future investigations to improve the prediction of the pyrolysis model.

After validating the pyrolysis model for moderate and low oxidizer mass flux, the extension to heterogeneous reaction is contemplated in very high oxidizer mass flux.

\section{Acknowledgments}

This research is supported by Region Occitanie and ONERA. We thank specially Mickaël Sicard from ONERA for his helpfully expertise on Thermogravitry analysis and Polymer properties.

\section{References}

[1] Odic, K., Denis, G., Ducerf, F., Martin, F., Lestrade, J.-Y., Verberne, O., Ryan, J., Christ, P., and de Crombrugghe, G., “HYPROGEO Hybrid Propulsion: Project Objectives and Coordination,” Space Propulsion, Rome, Italy, 2016. SP2016-3124697.

[2] Lestrade, J.-Y., Messineo, J., Hijlkema, J., Prévot, P., Casalis, G., and Anthoine, J., "Hybrid chemical engines: recent advances from sounding rocket propulsion and vision for spacecraft propulsion," AerospaceLab Journal, Vol. 11, 2016. doi:10.12762/2016.AL11-14.

[3] Anthoine, J., Lestrade, J.-Y., and Messineo, J., "Performances of a Multi-Pulsed Hybrid Rocket Engine Operating with Highly Concentrated Hydrogen Peroxide," 53rd AIAA/SAE/ASEE Joint Propulsion Conference, American Institute of Aeronautics and Astronautics, 2017. doi:10.2514/6.2017-4906. 
[4] Lestrade, J.-Y., Messineo, J., Anthoine, J., Musker, A., and Barato, F., "Development and Test of an Innovative Hybrid Rocket Combustion Chamber," 7th European Conference for Aerospace Science, 2017. doi:10.13009/EUCASS2017-414.

[5] Barato, F., Paccagnella, E., Venturelli, G., Scarpa, M., Picano, F., Pavarin, D., and Lestrade, J.-Y., "Numerical Simulation of an Isochoric Combustion Chamber for Hybrid Rocket Propulsion,” SP2016-3124745, 2016.

[6] Chiaverini, M., Serin, N., Johnson, D., Lu, Y.-C., Kuo, K., and Risha, G., "Regression Rate Behavior of Hybrid Rocket Solid Fuels," Journal of Propulsion and Power, Vol. 16, No. 1, 2000, pp. 125-132. doi:10.2514/2.5541, URL https: //doi.org/10.2514\%2F2.5541

[7] Chiaverini, M., and Kuo, K. K., Fundamentals of Hybrid Rocket Combustion and Propulsion, progress in astronautics and aeronautics ed., Vol. 218, AIAA, 2007. Pp. 104.

[8] Whitmore, S., and Merkley, S., "Effects of Radiation Heating on Additively Printed Hybrid Fuel Grain O/F Shift," 52nd AIAA/SAE/ASEE Joint Propulsion Conference, American Institute of Aeronautics and Astronautics, 2016.

[9] Marxman, G., and Gilbert, M., “Turbulent boundary layer combustion in the hybrid rocket,” Symposium (International) on Combustion, Vol. 9, No. 1, 1963, pp. 371-383. doi:10.1016/s0082-0784(63)80046-6, URL https://doi.org/10.1016\% 2Fs0082-0784\%2863\%2980046-6

[10] MUZZY, R., "Applied hybrid combustion theory," 8th Joint Propulsion Specialist Conference, American Institute of Aeronautics and Astronautics, 1972. doi:10.2514/6.1972-1143.

[11] ESTEY, P., ALTMAN, D., and MCFARLANE, J., "An evaluation of scaling effects for hybrid rocket motors," 27th Joint Propulsion Conference, American Institute of Aeronautics and Astronautics, 1991. doi:10.2514/6.1991-2517.

[12] Strand, L., Jones, M., Ray, R., and Cohen, N., "Characterization of hybrid rocket internal heat flux and HTPB fuel pyrolysis," 30th Joint Propulsion Conference and Exhibit, American Institute of Aeronautics and Astronautics, 1994. doi:10.2514/6.1994-2876.

[13] Glassman, I., Combustion, $2^{\text {nd }}$ ed., Academic Press, San Diego, U.S.A., 1987, pp. 360-375.

[14] Whitmore, S. A., Walker, S., Merkley, D., and Sobbi, M., "High Regression Rate Hybrid Rocket Fuel Grains with Helical Port Structures," Journal of Propulsion and Power, Vol. 31, 2015, pp. 1727-1738. doi:10.2514/1.B35615.

[15] Bianchi, D., Lapenna, P., Creta, F., and Nasuti, F., "Numerical Simulations of Flowfield and Combustion in Hybrid Rockets," Space Propulsion Conference, 2016. doi:SP2016-3125219.

[16] Bianchi, D., F., N., and D., D., "Modeling of Gas-Surface Interface for Paraffin-based Hybrid Rocket Fuels In CFD," 6th European Conference for Aerospace Science, 2015. doi:FP_EUCASS-368.

[17] Di Martino, G. D., Carmicino, C., and Savino, R., "Transient Computational Thermofluid-Dynamic Simulation of Hybrid Rocket Internal Ballistics,” Journal of Propulsion and Power, 2017, pp. 1-15. doi:10.2514/1.b36425, URL https://doi. org/10.2514\%2F1.b36425 
[18] Lin, J. L., "Two-phase flow effect on hybrid rocket combustion,” Acta Astronautica, Vol. 65, No. 7, 2009 , pp. $1042-1057$. doi:10.1016/j.actaastro.2009.03.020.

[19] Shan, F., Hou, L., and Piao, Y., "Combustion performance and scale effect from N2O/HTPB hybrid rocket motor simulations," Acta Astronautica, Vol. 85, 2013, pp. 1-11. doi:10.1016/j.actaastro.2012.12.013, URL https://doi.org/10.1016\%2Fj. actaastro.2012.12.013

[20] Bianchi, D., Leccese, G., Nasuti, F., and C., C., "Modeling of High Density Polyethylene Regression Rate in the Simulation of Hybrid Rocket Flowfields," 7th European Conference for Aerospace Science, 2017. doi:EUCASS2017-629.

[21] Faenza, M., Barato, L. M., F., and D., P., "Hybrid Rocket Motors Regression Rate Prediction through CFD Simulations," 6th European Conference for Aerospace Science, 2015.

[22] Cheng, G., Farmer, R., Jones, H., and McFarlane, J., "Numerical simulation of the internal ballistics of a hybrid rocket motor," 32nd Aerospace Sciences Meeting and Exhibit, American Institute of Aeronautics and Astronautics, 1994. doi: $10.2514 / 6.1994-554$.

[23] Leccese, G., Bianchi, D., and Nasuti, F., "Simulations of hybrid rocket flowfields including modeling of fuel pyrolysis and thermal radiation," Space Propulsion Conference, 2016.

[24] Leccese, G., Bianchi, D., and Nasuti, F., "Modeling of Paraffin-Based Fuels in the Simulation of Hybrid Rocket Flowfields," 52nd AIAA/SAE/ASEE Joint Propulsion Conference, American Institute of Aeronautics and Astronautics, 2016. $10.2514 / 6.2016-5066$.

[25] Leccese, G., Bianchi, D., Nasuti, F., Stober, K., Narsai, P., and Cantwell, B., "Simulations of Paraffin-Based Hybrid Rocket Motors and Comparison with Experiments," 53rd AIAA/SAE/ASEE Joint Propulsion Conference, American Institute of Aeronautics and Astronautics, 2017. doi:10.2514/6.2017-4737.

[26] Leccese, G., Bianchi, D., Nasuti, F., Stober, K., Narsai, P., and Cantwell, B., "Experimental and Numerical Evaluation of the Radiative Wall Heat Flux in the Post-Chamber of a Paraffin-Based Hybrid Rocket Engine," 7th European Conference for Aerospace Science, 2017. doi:EUCASS2017-149.

[27] Kim, H.-J., and Kim, Y.-M., "Numerical modeling for combustion processes of hybrid rocket engine," 37th Joint Propulsion Conference and Exhibit, American Institute of Aeronautics and Astronautics, 2001. doi:10.2514/6.2001-4504.

[28] Dua, S., and Ping, C., "Multi-dimensional radiative transfer in non-isothermal cylindrical media with non-isothermal bounding walls," International Journal of Heat and Mass Transfer, Vol. 18, No. 2, 1975, pp. 245 - 259. doi:10.1016/0017-9310(75)90157$\mathrm{X}$.

[29] Glowacki, J., Maggi, F., and Galfetti, L., "Numerical Simulation of Vortex Combustion in a Hybrid Rocket Motor," 7th European Conference for Aerospace Science, 2017. doi:10.13009/EUCASS2017-477. 
[30] Gariani, G., Maggi, F., and Galfetti, L., "Numerical simulation of HTPB combustion in a 2D hybrid slab combustor," Acta Astronautica, Vol. 69, No. 5-6, 2011, pp. 289-296. doi:10.1016/j.actaastro.2011.03.015, URL https://doi.org/10.1016\% $2 \mathrm{Fj}$.actaastro.2011.03.015

[31] Coronetti, A., and Sirignano, W., "Numerical Analysis of Hybrid Rocket Combustion," Journal of Propulsion and Power, Vol. 29, 2013, pp. 371-384. doi:10.2514/1.B34760.

[32] Siegel, R., and Howell, J., Thermal Radiation Heat Transfer, $4^{\text {th }}$ ed., Taylor and Francis, 2002.

[33] Carmicino, C., and Sorge, A., "Performance comparison between two different injector configurations in a hybrid rocket," Aerospace Science and Technology, Vol. 11, No. 1, 2007, pp. 61 -67. doi:10.1016/j.ast.2006.08.009, URLwWw. sciencedirect. com/science/article/pii/S127096380600143X

[34] Russ, A., Esposito, A., Quaranta, G., and Torella, G., "Regression rate measurements in a hybrid rocket," 36th AIAA/ASME/SAE/ASEE Joint Propulsion Conference and Exhibit, American Institute of Aeronautics and Astronautics, 2000. doi:10.2514/6.2000-3438.

[35] Lestrade, J.-Y., Anthoine, J., Verberne, O., Boiron, A. J., Khimeche, G., and Figus, C., "Experimental Demonstration of the Vacuum Specific Impulse of a Hybrid Rocket Engine,” Journal of Spacecraft and Rockets, Vol. 54, No. 1, 2017, pp. 101-108. doi:10.2514/1.a33467, URL https://doi.org/10.2514\%2F1.a33467.

[36] Lestrade, J.-Y., Prévot, P., Messineo, J., Anthoine, J., Casu, S., and Geiger, B., "Development of a Catalyst for High Concentrated Hydrogen peroxide," 6th International Symposium on Propulsion for Space Transportation (Space Propulsion), 2016.

[37] Refloch, A., Courbet, B., Murrone, A., Villedieu, P., Laurent, C., Gilbank, P., Troyes, J., Tessé, L., Chaineray, J., G.and Dargaud, Quémerais, E., and Vuillot, F., “CEDRE Software,” AerospaceLab Journal, Vol. 2, 2011. URL http://www . aerospacelabjournal.org/CEDRE-Software.

[38] Tessé, L., and Lamet, J.-M., "Radiative Transfer Modeling Developed at Onera for Numerical Simulations of Reactive Flows," AerospaceLab Journal, Vol. 2, 2011. URL http://www. aerospacelab-journal.org/al2

[39] Tessé, L., Dupoirieux, F., Zamuner, B., and Taine, J., "Radiative transfer in real gases using reciprocal and forward Monte Carlo methods and a correlated-k approach,” International Journal of Heat and Mass Transfer, Vol. 45, No. 13, 2002 , pp. 2797 2814. doi:https://doi.org/10.1016/S0017-9310(02)00009-1.

[40] Dupoirieux, F., Tessé, L., Avila, S., and Taine, J., "An optimized reciprocity Monte Carlo method for the calculation of radiative transfer in media of various optical thicknesses," International Journal of Heat and Mass Transfer, Vol. 49, No. 7, 2006, pp. 1310 - 1319. doi:https://doi.org/10.1016/j.ijheatmasstransfer.2005.10.009.

[41] Tessé, L., "Modélisation des transferts radiatifs dans les flammes turbulentes par une méthode de Monte Carlo," Ph.D. thesis, Ecole Centrale Paris, 2001. 
[42] Farmer, J. T., and Howell, J. R., "Comparison of Monte Carlo Strategies for Radiative Transfer in Participating Media," Advances in Heat Transfer, Vol. 31, edited by J. P. Hartnett, T. F. Irvine, Y. I. Cho, and G. A. Greene, Elsevier, 1998 , pp. 333 - 429. doi:https://doi.org/10.1016/S0065-2717(08)70243-0.

[43] Duval, R., "Transferts radiatifs dans les chambres de combustion de propulseurs à propergols solides aluminisés," Ph.D. thesis, Ecole Centrale Paris, 2002.

[44] Duval, R., Soufiani, A., and Taine, J., "Coupled radiation and turbulent multiphase flow in an aluminised solid propellant rocket engine," Journal of Quantitative Spectroscopy and Radiative Transfer, Vol. 84, No. 4, 2004, pp. 513 - 526. doi: https://doi.org/10.1016/S0022-4073(03)00268-1, eurotherm Seminar 73 - Computational Thermal Radiation in Participating Media.

[45] Soufiani, A., and Taine, J., "High temperature gas radiative property parameters of statistical narrow-band model for $\mathrm{H} 2 \mathrm{O}$, $\mathrm{CO} 2$ and CO, and correlated-K model for $\mathrm{H} 2 \mathrm{O}$ and CO2," International Journal of Heat and Mass Transfer, Vol. 40, No. 4, 1997, pp. 987 - 991. doi:https://doi.org/10.1016/0017-9310(96)00129-9.

[46] Tessé, L., Dupoirieux, F., and Taine, J., "Monte Carlo modeling of radiative transfer in a turbulent sooty flame," International Journal of Heat and Mass Transfer, Vol. 47, No. 3, 2004, pp. 555 - 572. doi:https://doi.org/10.1016/j.ijheatmasstransfer.2003. 06.003 .

[47] Westbrook, C. K., and Dryer, F. L., "Simplified Reaction Mechanisms for the Oxidation of Hydrocarbon Fuels in Flames," Combustion Science and Technology, Vol. 27, No. 1-2, 1981, pp. 31-43. doi:10.1080/00102208108946970. 